\title{
How to train your syllable stress awareness - A digital game-based intervention for German dyslexic children
}

\author{
Heiko Holz ${ }^{1,2}\left(\Xi^{\mathbb{D}}\right.$, Katharina Brandelik ${ }^{2}$, Benedikt Beuttler ${ }^{2,3}$, \\ Jochen Brandelik ${ }^{2}$, Manuel Ninaus ${ }^{1,4}$ \\ ${ }^{1}$ LEAD Graduate School \& Research Network, University of Tuebingen, Germany \\ heiko.holz@uni-tuebingen.de \\ ${ }^{2}$ Tübinger Institut für Lerntherapie, Germany \\ $\{k . b r a n d e l i k$, b.beuttler, j.brandelik\}@til-lerntherapie.de \\ ${ }^{3}$ Department of Psychology, University of Tuebingen, Germany \\ ${ }^{4}$ Leibniz-Institut für Wissensmedien, Tuebingen, Germany \\ m.ninaus@iwm-tuebingen.de
}

\begin{abstract}
Developmental dyslexia is one of the most frequent learning disorders and affects $4-10 \%$ of the German population. The learning disorder affects educational, personal, and social development of children in a negative way. We examine three different approaches to treat learning disorders. That is, therapeutic, computer-based, and digital game-based interventions. We reflect on the advantages and disadvantages of these approaches that have been shown to be supportive for dyslexic primary-school children. Our literature review shows that there is a lack of digital game-based interventions for the treatment of spelling disorders. To fill this gap, we propose such a mobile serious game which uses evidence-based trainings and introduces novel features in order to help dyslexic children to improve their reading and spelling performance. We propose an intervention to train awareness of syllable stress and explore the innovative use of mouth motor activities and embodied trainings. To conclude, we suggest that, in addition to traditional approaches, digital-game based approaches should be used supplementary to (re-) engage and motivate learners.
\end{abstract}

Keywords: Digital game-based learning, Dyslexia, Spelling, Syllable stress awareness;

\section{Introduction}

Approximately $4-10 \%$ of the German population suffer from developmental dyslexia [13]. Dyslexia is therefore one of the most frequent learning disorders [2]. It affects about 50.000 German children of each birth cohort.

These children acquire reading and writing skills in a much slower pace and not as proficient compared to their classmates [4] and they suffer massively from their impaired literacy acquisition. Usually, they lose their motivation for the learning process as well as the faith of being able to develop a comprehension of literacy language [5]. Appropriate treatments and interventions are necessary to prevent negative consequences, such as poor performance in school and higher chances to drop out from school, resulting in few employment prospects or unemployment [6]. Overall, the learning disorder has a negative impact not only on mental health but also on social and cultural participation [7].

On the one hand, it has been shown empirically that computer-based interventions can help dyslexic children to significantly improve reading and spelling skills (e.g., [8-12]). Interventions primarily address the symptoms of reading and writing disorders. Further, by the usage of game elements, such as narratives or rewards, they explicitly address issues related to frustration, demotivation or boredom [13] and support successful learning outcomes (cf. [14]). Mobile serious games can additionally help children to overcome their 
learning disorder outside of learning therapy and classrooms - independent of location and time. Importantly, mobile serious games for dyslexic children have been proven to have positive effects on the process of literacy acquisition (e.g., [15-17]).

However, there is a lack of evidence-based and empirically evaluated digital gamebased interventions for the treatment of spelling disorders in German dyslexic children.

In this article, we present such a mobile serious game called "Prosodiya". The evidencebased trainings of Prosodiya contribute three innovative features to the state of the art of computer-based interventions. First, it is the first digital therapy approach that focuses on improving the awareness of syllable stress and associates the stressed syllable's linguistic features to orthographic principles of the German orthography. It is thought that dyslexic children lack in accurate stress perception and thus fail to identify orthographic markers, which are particularly important in stress-timed languages such as German. Consequently, adequate processing verbal stress might support children acquiring complex spelling rules in German orthography (cf. Section 2.1). Second, mouth motor activities are introduced to support children that struggle to perceive phonological features. Lastly, the use of embodied training for mobile serious games using sensor-based gesture recognition are explored.

This article is structured as follows: First, we reflect the state of research of the relation between syllable stress and reading and spelling skills. This is followed by an overview of the different areas of reading and spelling acquisition and evidence-based trainings to address these areas. We then reflect advantages and disadvantages of three different approaches used for treatment of reading and spelling disorder, i.e. therapeutic, computerbased, and digital game-based interventions. In the fourth part of this article, we describe the current game and therapeutic design of Prosodiya. We conclude this article by reflecting the contributions of Prosodiya to the state of the art and by providing an outlook for the project's future progress with special focus on the opportunities of embodied trainings.

\section{$2 \quad$ Related work}

\subsection{Syllable stress and literacy acquisition}

Deficient phonological awareness is, among others, one major cause of dyslexia [18]. Phonological awareness refers to the ability to deal with the sound system of a language and to detect, distinguish, and manipulate segments of a language, such as syllables, rimes, or even single sounds (i.e. phonemic awareness).

Phonological awareness also includes the perception of prosodic features. A shortcoming in the perception of prosodic features is a strong predictor for developmental dyslexia [19-21]. One of these features is syllable stress, an important characteristic of German speech rhythm. German belongs to the category of stress-timed languages [22]. In stress-timed languages, speech rhythm is generated by the interval between two consecutive stressed syllables, which is perceived to be a fairly constant amount of time. Stressed syllables have larger rise times (the time required to reach peak signal intensity) in the amplitude envelope and are generally perceived to be louder. In contrast, unstressed syllables are compressed and reduced to fit the rhythm. Other typical stress-timed languages are, among others, English, Russian, Germanic languages, and European Portuguese. The rhythm of stress-timed languages differs to, among others, syllable-typed languages, such as Italian, French, or Spanish, in which the duration of every syllable is approximately constant in time.

Stress perception has been shown to be impaired for developmental dyslexics [19], [20, $23]$ and highly correlates with reading and writing skills [21, 24]. For German dyslexic children, one explanation is thought to be found in the association between stress and German orthographic markers. Orthographic markers - graphemes that mark vowel lengths - generally occur within stressed syllables [markers for long vowels, such as Bie-ne (bee)] or in conjunction with stressed syllables [markers for short vowels, such as Ge-wit-ter (thunderstorm)] [25]. Since the vowels of unstressed syllables are reduced, such as the 
schwa sound (/ə/) in /'ma:lən/ (malen, to paint), they are generally not marked orthographically.

The orthographic marking of short and long vowels, which underlies complex orthographic rules, is a major challenge for German dyslexic [26, 27]. Therefore, processing verbal stress adequately might help children to acquire the complex spelling rules that underlie vowel length spelling in German orthography.

Although research suggest that rhythmic trainings for poor English readers using, among others, exercises to match the correct syllabic stress pattern to words to be beneficial for the development of literacy and phonological awareness [28, 29], we are not aware of any (mobile) serious game that focusses on improving the awareness of syllable stress or associates the stressed syllable's linguistic features to orthographic principles of the German orthography.

\subsection{Evidence-based treatment of reading and spelling disorders}

According to the clinical guideline of diagnosis and treatment of German dyslexic children [30], the treatment of reading and spelling disorders can be divided into different areas. The authors infer recommendations for evidence-based trainings for each of these areas from the results of a meta-analysis [31,32] of randomized controlled field trials.

The areas of treatment of reading disorders comprise: i) syllabic and phonemic awareness, i.e. awareness of syllable and sounds, ii) reading accuracy, iii) reading fluency, and iv) reading and text comprehension. For the first stage, they recommend trainings to identify, categorize, segment, delete, or discriminate syllables and sounds within words. The second stage includes systematic instructions of letter-sound correspondences and exercises of phoneme synthesis. In this regard, derivational synthesis refers to blending (pulling together) individual parts of a language within words, e.g. blending individual sounds or syllables to words. Reading fluency should be trained with systematic exercises of phoneme, syllable, and morpheme synthesis. Lastly, reading comprehension includes interventions that comprise tasks in which participants learn to extract textual information, summarize it, and relate it to existing knowledge.

The areas of treatment of spelling disorders are: i) syllabic and phonemic awareness, ii) phoneme-grapheme correspondence, iii) grapheme memory entries, and iv) knowledge of rules and morphemes. The first stage of spelling acquisition equals to the first stage of reading promotion and thus provides the same interventional recommendations. For the second stage, phonics instruction (systematic instructions of letter-sound correspondences and exercises of phoneme analysis at the (sub-) lexical level) are recommended. For the latter, analysis refers to segmenting words into respective parts, e.g. phonemes or syllables. For the third stage, systematic exercises for storing and remembering frequent sequences of graphemes are recommended. Finally, exercises to acquire orthographic and morphemic regularities are recommended for the fourth stage of the treatment of spelling disorder.

The guideline [30] concludes that reading skills can be most effectively improved with systematic instruction of letter-sound correspondences and phoneme, syllable, and morpheme synthesis. Spelling performance can most effectively be improved by using systematic instructions of letter-sound correspondences and exercises analyzing sounds, syllables, and morphemes as well as trainings enabling the acquisition and generalization of orthographic regularities.

In the remainder of this article, we will mainly focus on interventions and trainings for German dyslexic primary school children. This is due to the fact that differences in orthographic consistency between languages, i.e. differences in regularity and consistency of letter-sound relations, result in differences in reading and spelling difficulties of dyslexic children and consequently the correct therapeutic approach [33-35]. German, due to regular letter-sound correspondences, has a high transparency of the writing system compared to languages with opaque letter-sound relations, such as English. 


\section{From therapeutic interventions to digital game-based learning}

Treatment of reading and spelling disorders yields different interventional approaches that can be applied. In this chapter, we take a closer look at therapeutic, computer-based, and digital game-based interventions for dyslexic children. By highlighting advantages and disadvantages of respective approaches, we deduce our general recommendation that therapeutic and digital-game based interventions should be used in the following way: Dyslexic children should receive evidence-based therapeutic interventions as soon as possible and as long as necessary until their reading and spelling proficiency enables them to participate in social, cultural, and educational life on an age-appropriate level. In addition, they should use evidence-based digital game-based interventions to maximize engagement, motivation, and learning.

\subsection{Therapeutic interventions}

The common approach to treat children suffering from learning disorders are therapeutic interventions (TI) administered in individual or group sessions. Therapeutic interventions are carried out by trained practitioners - such as teachers or learning therapists - in learning facilities, usually outside of school time (see Table 1).

If children participate in therapeutic interventions implementing aforementioned evidence-based approaches at least weekly for several months, substantial improvements in reading (e.g., [36-38]) and spelling (e.g., [9, 38, 39]) performance can be achieved.

Although children with reading and spelling disorders may show significant improvements after several weeks or months, they should receive support until their ability to read and spell reaches a level that enables them to participate in public life in an ageappropriate way [30]. This means in most cases several years of intense support and treatment. However, this may often not be provided if the healthcare system has no provision for funding [30]. This is the case in Germany - learning therapy is not covered by health insurances but by the youth welfare office. Applying for financing and reimbursement of learning therapy can be a tedious process disadvantaging families who cannot afford to pay for learning therapy privately. Thus, affected children may not receive appropriate treatment timely, sustainably, or long enough.

Importantly, it is strongly recommended that interventions should be implemented by experts in reading and spelling development and its promotion [30] rather than by peers, parents, or university students - which might come to mind to affected families as a costeffective alternative but whose effectiveness could not be confirmed unequivocally [31, 40].

To conclude, evidence-based therapeutic interventions are reliable and recommended treatments for dyslexic children when administered by experts but are cost-intensive and might not be provided timely or long enough.

\subsection{Computer-based interventions}

Computer-based interventions (CBI) and the use of information and communication technology (ICT) have been shown to benefit learning-impaired children. By complementing therapeutic interventions and traditional teaching, they address the aforementioned disadvantages of TI and offer new opportunities to engage the learner (se also Table 1). Based on literature reviews, we conclude that CBI and ICT can have positive effects on dyslexic children's learning development [41] and that they facilitate literacy acquisition for dyslexic children by minimizing difficulties in learning to read and write [42].

First, one of the major advantages of CBIs is that they can be used independent of time and place, outside of class or learning therapy. 


\begin{tabular}{|c|c|c|c|c|c|c|c|c|c|c|}
\hline \multirow{3}{*}{ 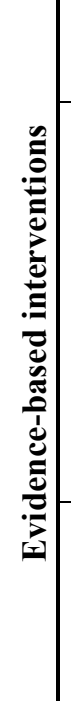 } & $\begin{array}{c}\dot{\pi} \\
\dot{\pi} \\
\text { | }\end{array}$ & $+\quad+$ & I & + & + & + & + & Ð & 1 & ક \\
\hline & 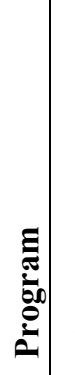 & 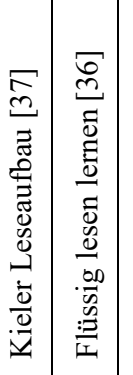 & 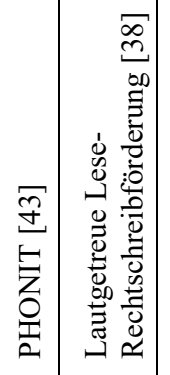 & 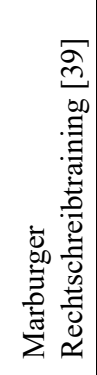 & 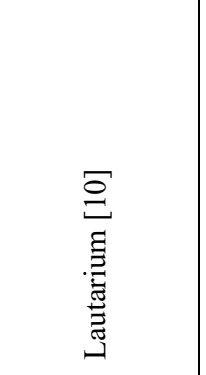 & $\begin{array}{l}\bar{a} \\
0 \\
\bar{z} \\
\bar{z} \\
\overline{0} \\
\sum\end{array}$ & 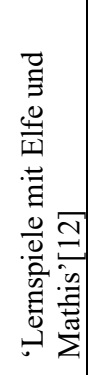 & 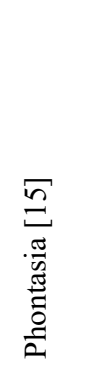 & 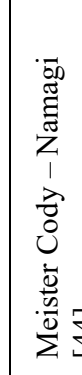 & 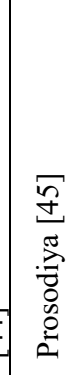 \\
\hline & $\begin{array}{l}0 \\
\vdots \\
0 \\
0 \\
1\end{array}$ & $\begin{array}{l}\stackrel{0}{\Xi} \\
\stackrel{\Xi}{\Xi} \\
\simeq\end{array}$ & \multicolumn{2}{|c|}{$\begin{array}{l}\stackrel{\infty}{\Xi} \\
\overline{\bar{D}} \\
\text { के }\end{array}$} & 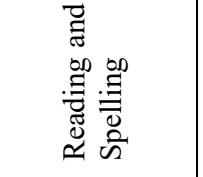 & $\begin{array}{l}\stackrel{0}{\Xi} \\
\overline{\bar{D}} \\
\stackrel{0}{\infty}\end{array}$ & $\begin{array}{l}\stackrel{\infty}{\Xi} \\
\stackrel{\Xi}{\Xi} \\
\simeq\end{array}$ & $\begin{array}{l}\stackrel{\infty}{.} \\
\overline{\bar{D}} \\
\stackrel{0}{n}\end{array}$ & 胥 & $\frac{\infty}{\stackrel{\Xi}{\bar{D}}}$ \\
\hline 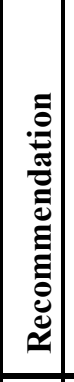 & \multicolumn{4}{|c|}{ 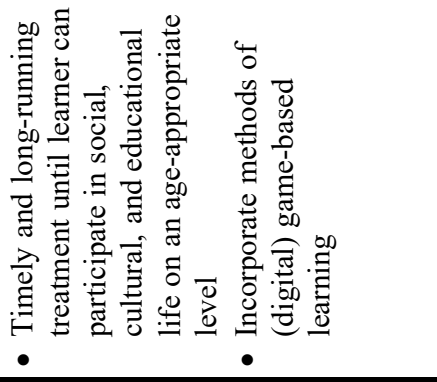 } & \multicolumn{2}{|l|}{ 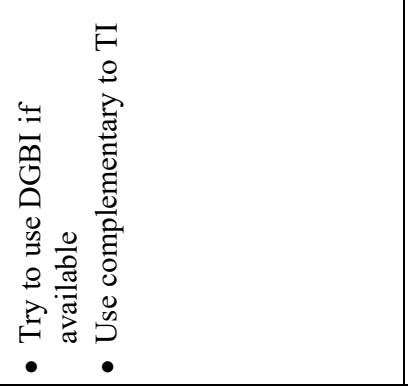 } & \multicolumn{4}{|c|}{ 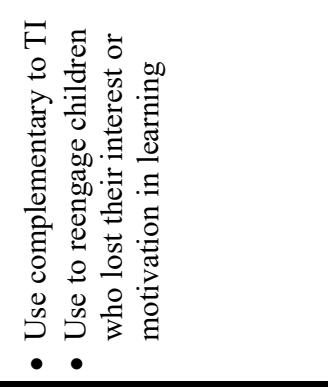 } \\
\hline 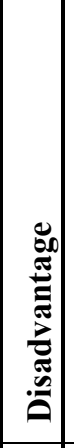 & \multicolumn{4}{|c|}{ 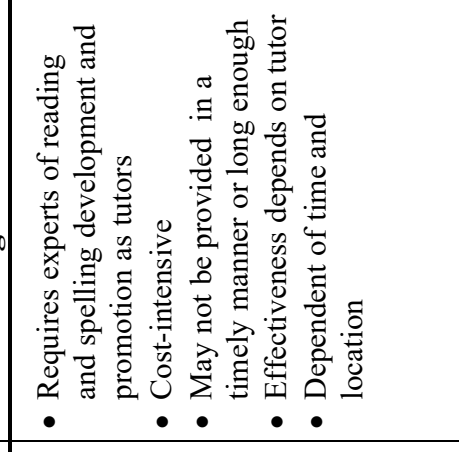 } & \multicolumn{2}{|c|}{ 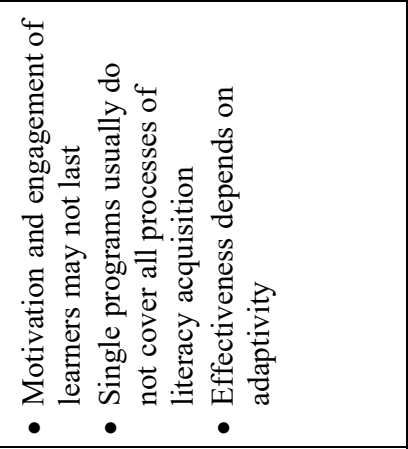 } & \multicolumn{4}{|c|}{ 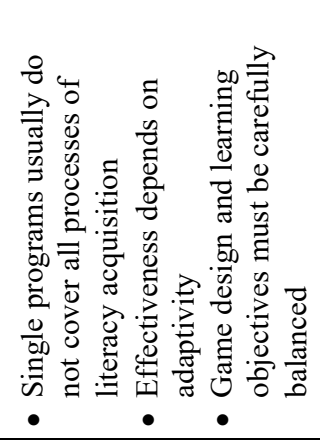 } \\
\hline \multirow[t]{3}{*}{ 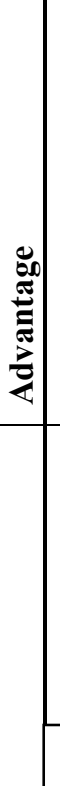 } & \multicolumn{4}{|c|}{ 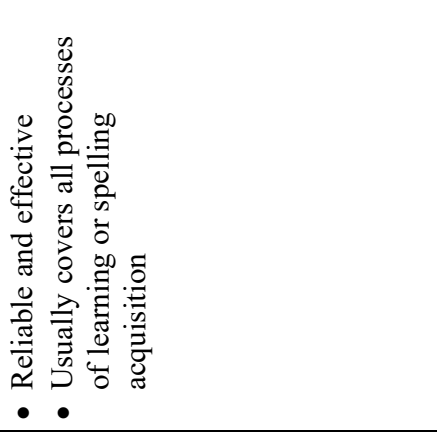 } & \multicolumn{2}{|c|}{ 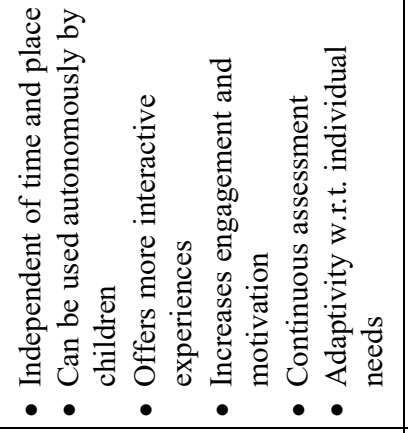 } & \multicolumn{4}{|c|}{ 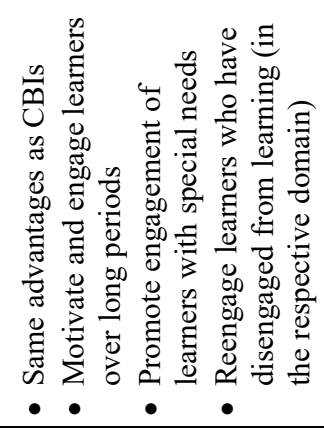 } \\
\hline & & 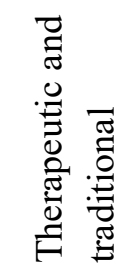 & & & 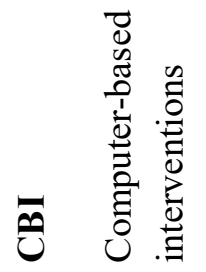 & & 馬 & $\stackrel{\vec{\omega}}{.00}$ & 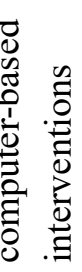 & \\
\hline & \multicolumn{4}{|c|}{ sołm urunh } & \multicolumn{6}{|c|}{ 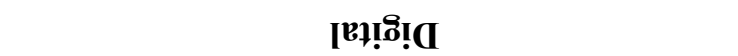 } \\
\hline
\end{tabular}


Second, if designed properly, learners can use CBIs autonomously for homework complementary to school and learning therapy without a real tutor. In fact, dyslexic children may respond to explicit computer instructions in writing as well as they have with human teachers [46].

Third, research has shown that children may concentrate better while engaged in CBI than in traditional school tasks [47]

Fourth, nowadays, ICT can provide interactive experiences which can motivate children at an early age and attenuate the impact of their own difficulties in the daily acquisition of reading and spelling skills [42].

Fifth, CBIs may offer continuous and more frequent assessment of proficiencies and knowledge $[48,49]$ compared to TI and save time in administration and evaluation of tests.

Through continuous assessment, CBIs are able to recognize individual needs of dyslexic children, which has been emphasized to be important for automatically adapting a CBI [50] - adaptivity is a common requirement posed to CBIs.

Lastly, gamification plays a major role in CBI. Gamification as defined by Deterding et al. [13] is the use of game design elements in non-game contexts, such as narratives, scores, or rewards. The role of gamification is primarily in invoking the same psychological experiences as games generally do [51]. Based on the literature review of Hamari et al. [52], gamification in educational and learning contexts mostly positively affects learning. Most importantly, it increases motivation, engagement in, and enjoyment of learning tasks [52].

Lautarium [10] is an adaptive computer-based intervention program for primaryschool. It includes training to improve phonological awareness in the narrow sense (e.g., phonemic awareness, phoneme analysis and synthesis, phoneme classification) as well as letter-sound correspondence to foster pronunciation-true reading and spelling. The authors of Lautarium could show empirically in a waiting control group design its efficacy on phonemic and phonological awareness and pronunciation-true reading and spelling [10].

Morpheus [9] is a computer-based spelling training that focuses on improving morphemic awareness, i.e. the ability to recognize, understand, and use morphemes. Morpheus trains orthographic regularities for the categories of consonant doubling, silent $\mathrm{h}$, and German vowel doubling ie. It additionally trains orthographic phenomena that may not be deduced from phonetic principles. It has been shown empirically in a control-group design that Morpheus significantly improves morphemic spelling strategies [9].

\subsection{Digital game-based interventions}

Digital game-based interventions (DGBI) are the top tier of digital interventions for children with learning disorders. DGBI are extensions to CBI in that they include all benefits of CBIs (as they belong to the same technology, namely digital) but address CBIs' drawback of not fully exploiting the engaging and motivational potential of digital games (see Table 1).

Crucially, we differentiate between gamified CBI and DGBI as follows: gamified interventions merely incorporate elements of games while game-based learning or serious games describe the design of full-fledged games for educational purposes [13] that focus on designing activities as playful tasks [53]. We additionally refer to the definition of Wouters et al. [54] of digital games to be interactive, based on a set of agreed rules and constraints, directed toward a clear goal that is often set by a challenge, and constantly providing feedback either as a score or changes in the game world to enabled selfmonitoring of progress towards the goal.

As gamified CBIs are often advertised as educational games, it is important to highlight that this claim may result in negative consequences due to the expectations posed to educational games: Parents and children consider enjoyment as one of the central principles important in educational software that is used in the home environment [55] and sometimes even prioritize enjoyment above educational benefits. As DGBIs are expected to be engaging and fun and thus naturally motivating $[55,56]$, the motivational design of DGBIs 
used in the home environment is of crucial importance, whereas learning effectiveness is referred to the most essential aspect at school [56]. Therefore, labeling CBIs as games may fail to live up to these expectations if the use of game is limited to gamification.

\subsubsection{The advantages of digital game-based interventions}

The benefits of game playing as a learning process are widely acknowledged $[57,58]$. DGBIs have been found to be effective or even outperform conventional instruction methods in terms of learning and retention, such as lectures, reading, drill and practice, or hypertext learning environments [54]. In fact, this is particularly the case for language learning as highlighted by the meta-analysis of Wouters et al. [54]. DGBIs are able to promote engagement and learning for children with special learning needs [59] and may boost children's engagement with literacy activities, foster skill reinforcement, and enhance the perception of reading progress [60] - DGBIs may even reengage learners who disengage from learning, i.e. learners who lost interest, motivation, and engagement in learning and cannot be engaged with other methods [61,62] (see Table 1). DGBIs are also especially suited to foster learning through embodied cognition, i.e. mapping of gestures or movement to key features of the content to be learned [53]. For example, in a Kinect-based literacy game, using gestures and movements in in-game activities enhanced literacy outcomes of children compared to a group without these activities [63]. The concept and implication of motion-based trainings is discussed more thoroughly in Section 5 .

Importantly, due to fact that DGBIs focus on defined learning outcomes, balancing educational effectiveness and quality of learning with game play is a corollary to the design process of DGBIs [53, 59, 64, 65]. If this is accounted for, DGBIs are able to engage learners on an affective, behavioral, cognitive, and sociocultural level in ways few other learning environments are able to do - as emphasized by the integrated design framework of game-based and playful learning by Plass et al. [53].

Phontasia [66] is a game-based German phonics trainer available for iPads. It is derived from the phonics method for English spelling acquisition and is adjusted for German. Children learn orthographic regularities by changing a defined set of graphemes to form a word. By providing artificial text-to-speech synthesis, children can listen to their solutions. This way, misspellings and correct spellings can be made audible for each of the children's solutions and children may reflect on their answer. Preliminary results of two evaluations indicate that Phontasia has positive effects on the spelling of consonant doublings and the German vowel doubling ie [15,67].

'Lernspiele mit Elfe und Mathis' [12] is a computer-based game for reading acquisition. Its content is categorized in linguistic levels of phonemes and syllables, words, sentences, and texts. Various exercises cover, among others, letter-sound correspondence, syllable synthesis, syllable analysis, and reading comprehension. Elfe was evaluated empirically in a randomized waiting control group design [12]. The authors could show significant effects of the training on reading performance on the level of words, sentences, and texts.

Meister Cody - Namagi [44] is an evidence-based DGBI for reading acquisition. It offers exercises to improve phonemic awareness (e.g., vowel-length distinction, recognition of initial and final sounds), phonological awareness (e.g., syllable analysis and synthesis), letter-sound correspondences, and semantic linking of words with pictures. Exercises to improve spelling are currently under development. Namagi has not yet been empirically evaluated.

\subsection{Categorization of computer-and digital game-based interventions for German dyslexic primary school children}

In addition to Table 1, we categorized the evidence-based computer- and digital gamebased interventions discussed in the previous section with regards to the areas of the treatment of reading and spelling disorders in Table 2 . An intervention receives a ' + ' for a 
pag. 44

specific area if it contains explicit instructions and exercises, '( +$)^{\prime}$ ' if exercises may implicitly support the area, and '-' if the intervention does not include exercises to promote a specific area of reading or spelling. Combining Table 1 and Table 2, parents and practitioners may select interventions according to a child's need.

Table 2. Categorization of popular evidence-based interventions according to the areas of the treatment of reading and spelling disorders (derived from [30]).

\begin{tabular}{|c|c|c|c|c|c|c|c|c|c|}
\hline \multirow[t]{2}{*}{ App } & \multicolumn{4}{|c|}{ Treatment of reading disorder } & \multicolumn{4}{|c|}{ Treatment of spelling disorder } & \multirow{2}{*}{ Eval. } \\
\hline & $\begin{array}{l}\text { Awareness } \\
\text { of syllables } \\
\text { and sounds } \\
\end{array}$ & $\begin{array}{l}\text { Reading } \\
\text { accuracy }\end{array}$ & $\begin{array}{l}\text { Reading } \\
\text { fluency }\end{array}$ & $\begin{array}{l}\text { Reading/text } \\
\text { comprehens. }\end{array}$ & $\begin{array}{l}\text { Awareness } \\
\text { of syllables } \\
\text { and sounds } \\
\end{array}$ & \begin{tabular}{|c|} 
Letter- \\
sound \\
correspond.
\end{tabular} & $\begin{array}{l}\text { Memory } \\
\text { retrievals }\end{array}$ & $\begin{array}{l}\text { Knowledge } \\
\text { of rules and } \\
\text { morphemes }\end{array}$ & \\
\hline \multicolumn{10}{|c|}{ Computer-based interventions } \\
\hline $\begin{array}{l}\text { Lautarium } \\
{[10]}\end{array}$ & $(+)$ & + & + & - & + & + & - & $(+)$ & + \\
\hline $\begin{array}{l}\text { Morpheus } \\
\text { [9] }\end{array}$ & - & $(+)$ & $(+)$ & - & - & - & + & + & $(+)$ \\
\hline \multicolumn{10}{|c|}{ Digital game-based interventions } \\
\hline Elfe [12] & + & + & + & + & + & $(+)$ & + & $(+)$ & + \\
\hline $\begin{array}{l}\text { Phontasia } \\
{[15]}\end{array}$ & $(+)$ & - & + & - & $(+)$ & + & + & + & $(+)$ \\
\hline $\begin{array}{l}\text { Namagi } \\
{[44]}\end{array}$ & + & + & + & - & + & + & - & - & - \\
\hline Prosodiya & + & $(+)$ & $(+)$ & - & + & + & + & + & $(+)$ \\
\hline
\end{tabular}

\subsection{Intermediate conclusion}

Therapeutic, computer-based, and digital game-based interventions play a major role in the treatment of reading and spelling disorders. Each approach comes with advantages and disadvantage as discussed above. This chapter is summarized in Table 1 and Table 2 by providing a list of advantages, disadvantages, exemplary programs that incorporate evidence-based approaches for the treatment of reading and spelling disorders, and practical recommendations.

It is important to state that CBIs and DGBIs should be used as a supplementary tool within or outside class in assisting dyslexic children but may not replace traditional teaching and learning strategies or therapeutic interventions $[11,68]$.

To conclude this chapter, we recommend to treat dyslexic children with evidence-based therapeutic and traditional interventions as soon as possible and as long as necessary until their reading and spelling proficiency enables them to participate in social, cultural, and educational life on an age-appropriate level. Additionally, we recommend the integration of DGBIs in TIs and the use of DGBIs complementary to TIs, outside of class, to (re-) engage and motivate learners in ways withheld to TIs.

As can be drawn from Table 1, evidence-based and empirically evaluated DGBIs for the treatment of spelling disorders are missing for German dyslexic children. With Prosodiya, we intend to fill this gap.

\section{Prosodiya}

We define Prosodiya as a DGBI based on the definition of Plass et al. [53] that it's a game for an educational purpose and focusses on designing activities as playful tasks, i.e. carefully concerning the balance of the design of learning objectives and game play. The most important arguments for DGBIs as described by Plass et al. [53] are motivation, engagement, adaptivity, and graceful failure. To address these arguments researchers mostly agree on the following building blocks of DGBIs: game mechanics, visual aesthetic design, narrative design, incentive system, and content and skills [53]. 
Accordingly, we use these buildings blocks to analyze and describe our game in the following sections after providing a general description of Prosodiya's rationale.

Prosodiya is based on recent empirical findings and on evidence-based interventions (e.g., $[39,69])$. For example, a main component is training phonological awareness in the broader sense (syllable awareness) as well as in the narrow sense (phonemic awareness) as children with dyslexia often struggle with this basic skill $[18,70]$.

Prosodiya builds on the research reflected in Section 2.1 and primarily aims at training detection and production of syllable stress - a feature that is not found in other serious games. First, this might improve a child's ability to segment words into relevant components. Second, children learn to focus on relevant areas in words. Prosodiya is played on tablets with a touchscreen interface. It aims at clarifying the association between syllable stress and orthographic marking. It helps children to focus on the stressed syllable and to learn how such syllables are spelled. In doing so, it finally leads to a rule-based orthographic spelling training. Prosodiya includes six chapters, each corresponding to a different linguistic or orthographic challenge.

The focus of Prosodiya is primarily on spelling acquisition by training the awareness of linguistic features related to syllable stress and by linking these features to orthographic regularities of German orthography. However, most exercises also cover skills that contribute to promotion of reading. Thus, our pedagogical approach enabling acquisition and application of orthographic knowledge is in line with empirical research emphasizing that acquisition and generalization of orthographic regularities is an essential part of effective methods to improve spelling performance [31, 39, 71, 72].

The game's overall narrative revolves around little inhabitants called "Kugellichter" (spherical lights), which seek for help of the children: A mysterious fog has conquered the land of Prosodiya which causes the inhabitants to live in sadness, see Figure 2a. Only the children, with the help of the Kugellichter, can disperse the suppressing fog by mastering linguistic challenges. Each time the children make progress within the course of the game, parts of Prosodiya are saved and new regions with new challenges call for their help.

The difficulty of Prosodiya increases on three individual levels: First, the game's chapters cover different linguistic or orthographic skills that range from syllable stress awareness to applying spelling rules. Second, subchapters within a chapter target different linguistic or orthographic sub-competences, which is explained in the following sections. Third, the levels increase in difficulty in that the target words' structures become more complex and objective(s) of tasks become more challenging by continuously decreasing the support provided to children to solve an exercise. By automatically increasing and decreasing the difficulty on individual levels, Prosodiya accounts for one of the four arguments of DGBI, namely adaptivity.

In the following, we give a detailed description of Prosodiya's game mechanics, content and skills to be learned, visual aesthetic design, narrative design, and its incentive system. Short video clips of Prosodiya are listed on youtube.prosodiya.com. A general overview of the therapeutic structure of the first module of Prosodiya is displayed in Figure 1.

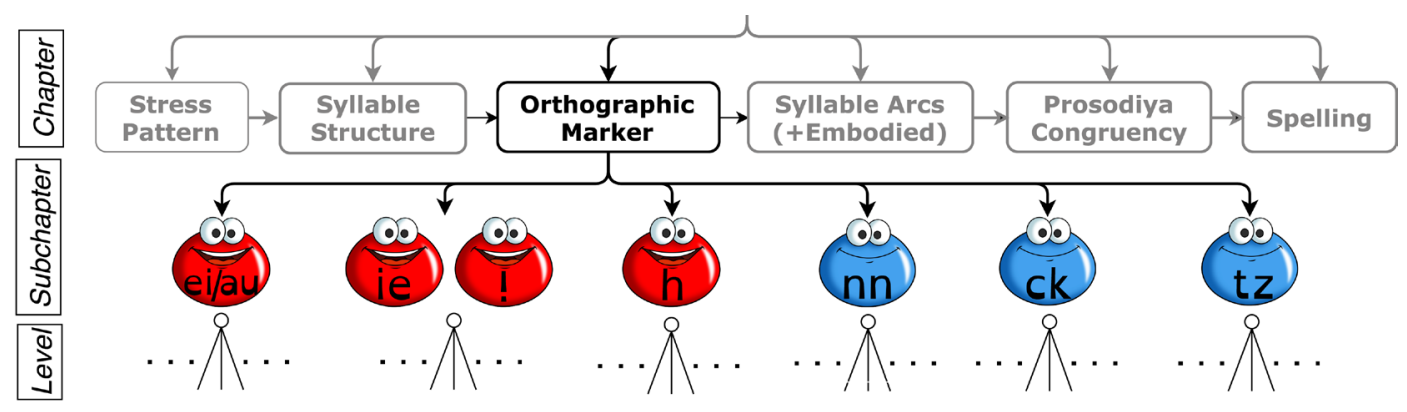

Figure 1. Overview of the interventional structure of the first module of Prosodiya.

As the first module of Prosodiya attributes orthographic regularities to the basic (uninflected) form of words, morphologic inflection, i.e. conjugation and declension, is not 
pag. 46

yet covered. Morphologic training, i.e. to learn to deduce that gewinnt (he wins) is spelled with an ambisyllabic consonant doubling as it's derived from gewinnen (to win), is part of the second module of Prosodiya currently being developed.

\subsection{Game mechanics and content and skills}

We combine two game design elements, i.e. game mechanics and content and skills, in one section as the latter game design element is significantly responsible for the design of game mechanics. As Prosodiya's primary learning goal is to improve spelling, the game serves the function to teach new knowledge and skills as well as practice and reinforce existing knowledge and skills. The game mechanics have been carefully designed and refined based on the results of usability tests to ensure high quality of learning and gaming experience. All game mechanics are explained in interactive tutorials, see Figure $2 b$.

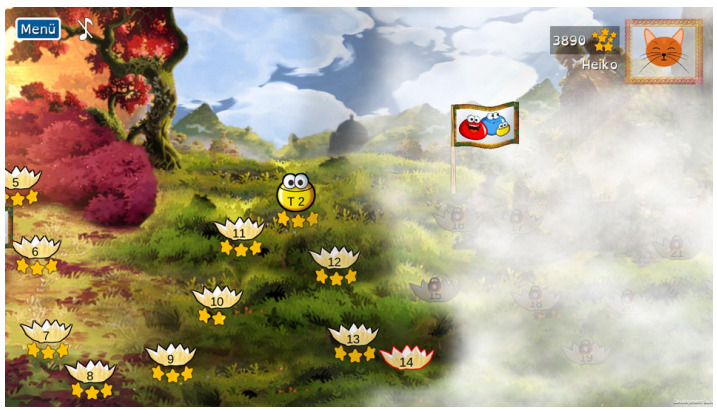

a. In-game map of Prosodiya.

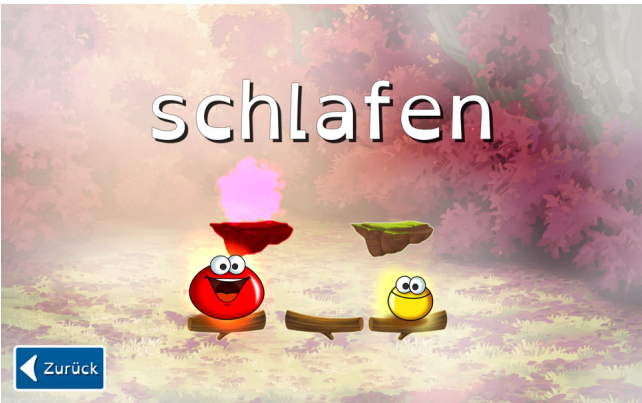

b. Tutorial of "Syllable Structure".

Figure 2. In-game map of Prosodiya and exemplary tutorial of the game "Syllable Structure".

\subsubsection{Stress pattern}

The game starts by introducing the children to the concept of syllable stress. Characterizations of stressed (larger rise-times and amplitude, non-reduced vowels) and unstressed syllables (reduced vowels) are explained in tutorials. Children are taught to apply this knowledge by rebuilding stress patterns of words to develop awareness for relevant phonological features. They do so by dragging and dropping cartoon blobs (big green blob for stressed syllables, small yellow blobs for unstressed syllables) onto their respective platforms, see Figure 3. This first task aims at drawing a child's attention to the stressed syllable and to the area of the word in which orthographic markers occur, respectively. This is the most innovative training exercise of Prosodiya with respect to state of the art interventions, and it specifically addresses the shortcomings of dyslexic children. That is, improving the perception and production of syllable stress, which is not part of any empirically evaluated or computer-based intervention for German dyslexic children. We have opted to use the interaction of dragging and dropping the blobs instead of other gaming activities, such as a multiple choice task, as this best directs finger and eye movement of children to the area of interest, i.e. stressed syllables.

During the course of Prosodiya's first chapter, we adjust the difficulties of different parameters to explicitly address syllabic and phonemic awareness as well as syllable synthesis, analysis, and segmentation. Parameter combinations that lead to a training of a specific linguistic competence are listed in Table 3.

The game begins with the easiest configuration displayed in Figure 3a: words are presented in spoken form, the number of syllables is exposed by only providing as many platforms as the word's syllable count, and the word is displayed syllabified in written form. Thus, this configuration provides training of syllable synthesis (blending the presented syllables into words) and syllable and phonemic analysis (identifying the stressed syllable). By displaying words non-syllabified, syllable segmentation is addressed additionally. 
Table 3. Linguistic competences trained in the game "Stress Patterns". Different parameter settings address different competences in different degrees.

\begin{tabular}{l|c|c|c|c|c|c|c}
\hline \multicolumn{1}{|c|}{ Parameter } & \multicolumn{1}{c|}{$\begin{array}{c}\text { Word is } \\
\text { spoken }\end{array}$} & \multicolumn{2}{c|}{ Visual presentation } & \multicolumn{2}{c}{$\begin{array}{c}\text { Number of } \\
\text { syllables }\end{array}$} \\
\hline & \multicolumn{2}{|c|}{} & \multicolumn{2}{|c|}{ written } & image & \multicolumn{2}{c}{} \\
\hline & yes & no & syllabified & $\begin{array}{c}\text { non- } \\
\text { syllabified }\end{array}$ & & exposed & $\begin{array}{c}\text { not } \\
\text { exposed }\end{array}$ \\
\hline $\begin{array}{l}\text { Awareness of syllables and } \\
\text { sounds }\end{array}$ & + & + & + & + & + & + & + \\
\hline Syllable synthesis & - & + & + & + & + & + & + \\
\hline Syllable segmentation & + & + & - & + & + & - & + \\
\hline
\end{tabular}

In case the word is not presented in spoken form (Figure 3b), we further aim at training syllable synthesis. By providing more platforms than the word has syllables, children are also required to count syllables autonomously (Figure 3c). As the level of difficulty and complexity changes during the course of these exercises, we provide mini-tutorials and tooltips that clarify explicitly what the children need to do and what they need to take into account in order to solve an exercise. An exemplary tooltip can be seen in Figure 4b.

We provide three different sound files for each word that increase with regard to the intensity of intonation. If a wrong answer is submitted or children request help, the word is spoken in the next stronger intonation level to give scaffolding feedback.

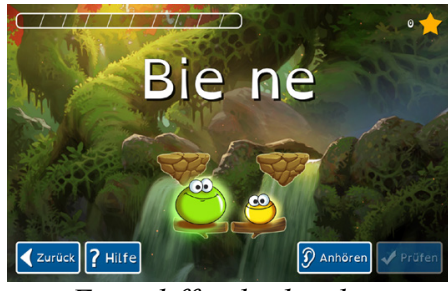

a. Easy difficulty level.

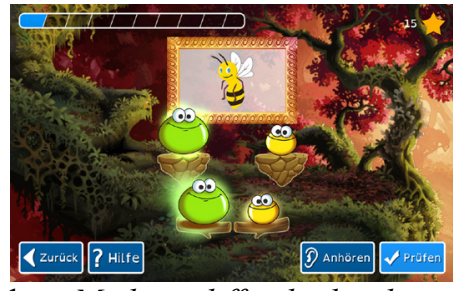

b. Medium difficulty level.

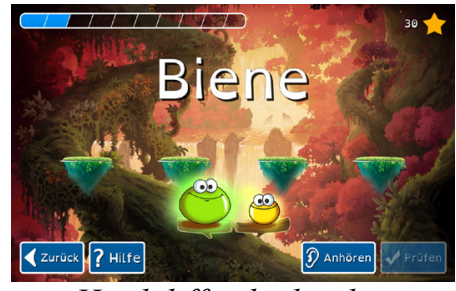

c. Hard difficulty level.

Figure 3. Different difficulty levels of Prosodiya's first chapter "Stress Pattern" for the word Bie-ne (bee). a) Syllabification as well as number of syllables are exposed to the learner. b) The word is no longer presented in written form but number of syllables is exposed. c). Neither number of syllables nor syllabification are exposed to the learner, requiring syllable segmentation to solve the exercise.

\subsubsection{Syllable structure}

The second type of games provided in Prosodiya focusses on syllable structure and builds upon the competence of stress pattern recognition. First, children need to detect the stressed syllable. Then, they have to decide whether the stressed syllable is open (ends with a long vowel) or closed (ends with a consonant). Here, we introduce awareness of mouth motor activity. Children learn that at the end of open syllables, the mouth is open: they can lengthen the vowel, thus keeping the mouth open. At the end of closed syllables however, the mouth is closed: a consonant "stops" the vowel and "squeezes" it, the mouth is closed at the lips, the teeth, or by the tongue. Depending on these structures, there are different orthographic markers [25]. Therefore, processing the structure of the stressed syllable is a base for acquiring the complex spelling rules that underlie spelling of long vs. short vowels in German orthography. Figure 4a displays a sample exercise of the game's second chapter.

Trainings to distinguish vowel length are commonly used in empirically evaluated interventions of reading and spelling acquisition and is not by itself a novelty. However, we introduce two novel features to computer-based treatments that have not been addressed before: First, we link the linguistic characteristics of syllable stress to vowel length. Second, we use the mouth features of the blobs and the terms of open vs. closed syllables instead of long vs. short vowels in order to support mouth motor activity. 


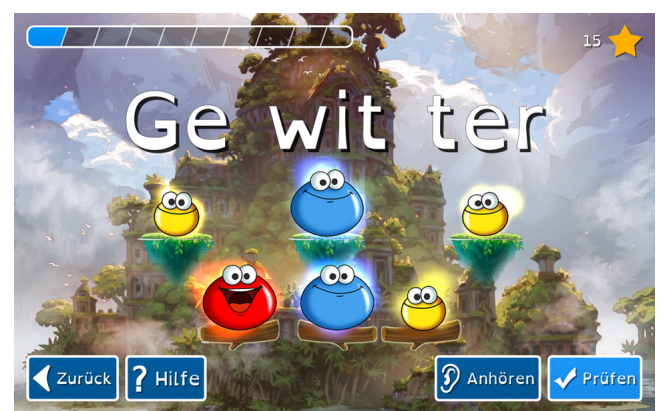

a. "Syllable Structure": Gewitter (thunderstorm).

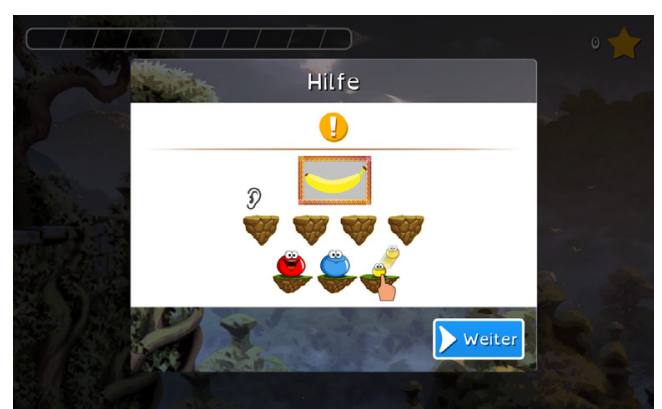

b. Exemplary tooltip of "Syllable Structure".

Figure 4. "Syllable Structure". a) Red blobs with mouths open refer to open stressed syllables (i.e., end with vowels) and blue blobs with mouths closed refer to closed stressed syllables (i.e., end with consonants). b) Shows a tooltip for this game. Children are told to i) find the open/closed syllable, ii) that the word is read out and represented by an image but not written, and iii) that they have to count the syllables autonomously.

Children with dyslexia have difficulties permeating the sound level of a language in order to improve letter-sound correspondence on the segmental level [73]. Mouth motor activity, which is intact for dyslexic children [4], can be used to facilitate learning of lettersound correspondence [74]. By teaching the children to pay attention to their mouth motor activities at the end of the stressed syllables, we aim at facilitating the process of vowel length distinction.

We also provide sound files of minimal pairs for each word. These minimal pairs consist of the word itself and the pseudoword counterpart for which the vowel length of the stressed syllable was changed to the contrary, i.e. long vowels are spoken as short vowels (e.g., Bie-ne vs. Bin-ne) and short vowels are spoken as long vowels (e.g., Ge-wit-ter vs. Ge-wie-ter). These minimal pairs are provided when wrong answers have been submitted or when help is requested. This way, we explicitly train vowel length perception and distinction as well as provide scaffolding feedback.

The difficulty as well as the target linguistic competences are defined by the same adjustments of parameters as in the game's first chapter.

\subsubsection{Orthographic markers}

After acquiring the knowledge about the structures of stressed syllables, children are exposed to the spelling of these structures in the game's third chapter. In interactive tutorials, they acquire metalinguistic knowledge about the rules that underlie the spelling of open and closed syllables. Thus, this type of game focuses on learning orthographic and morphemic regularities and letter-sound correspondences. Children train the recognition of orthographic markers for open and closed syllables, which are listed in Figure 5, in various minigames. The vowel of an open syllable can either be i) unmarked (e.g., ma-len, to paint), ii) marked with a vowel doubling such as diphthongs (e.g., Dau-men, thumb) or the German long i (e.g., Bie-ne, bee), which also has unmarked exceptions (e.g., Ti-ger), or iii) marked with the silent h (e.g., feh-len, to miss). Closed syllables with simple structures are i) unmarked (e.g., Fel-sen, rock). Closed syllables with the more complex structure of ambisyllabic consonants are ii) marked with doublings (e.g., ge-win-nen, to win). Additionally, German consonant doubling comes with two special subtypes: iii) $c k$ instead of $k k$ as in Ha-cke (pick) and $t z$ instead of $z z$ as in Hit-ze (heat).

Blobs represent each of the above mentioned orthographic realizations. The children need to select the Blob that represents the vowel spelling of the stressed syllable (e.g., Figure 5b). This chapter contains in total six subchapters, each dealing with one of the special orthographic rules. The characteristics of each of the orthographic markers are explained in individual tutorials. 


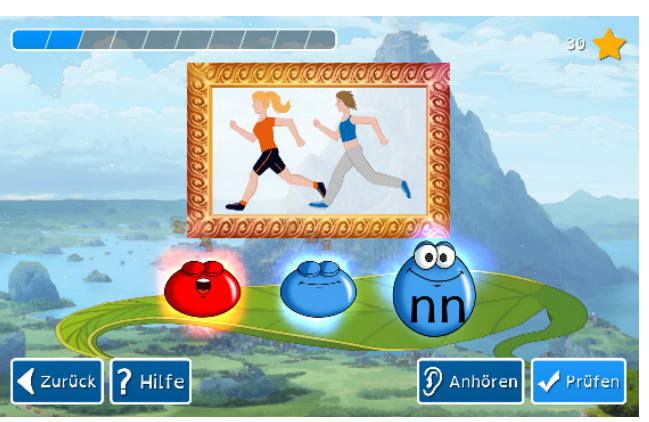

a. Ambisyllabic consonant doubling: rennen (to run).

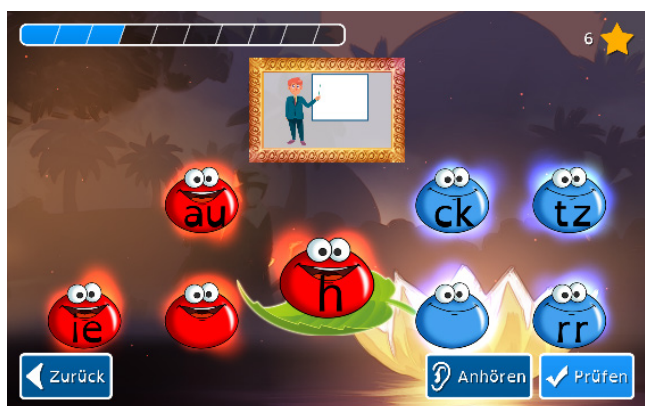

b. Consolidation task: Lehrer (teacher).

Figure 5. "Orthographic Markers". a) Children need to recognize if the displayed word ren-nen (to run) contains a long or short vowel and for the latter case whether the short vowel is marked orthographically with an ambisyllabic consonant doubling. b) Consolidation task with all orthographic markers. Displayed is the word Leh-rer (teacher), whose long vowel is marked orthographically with a silent $h$.

For example, ambisyllabic consonant doublings (e.g., nn, ck, tz) are explained to generally appear if the vowel of the stressed syllable is followed by a single consonant phoneme before the next vowel is perceived or the word ends [e.g., ren-nen (to run) vs. fin-den (to find)].

This chapter is of special importance as training to recognize orthographic markers is crucial for spelling [26,31]. Algorithms of spelling rules to detect and apply orthographic markers are used in various evidence-based treatments (e.g., [39, 75], cf. [31]). However, to the best of our knowledge, the algorithms to determine orthographic marking of vowel length have not been related to syllable stress in any computer-based intervention before.

Step by step, the number of blobs the children can choose from increases. Additionally, the similarity of distracting blobs varies. Exemplary tasks can be seen in Figure 5.

\subsubsection{Syllable arcs}

Prosodiya's fourth chapter is about syllable segmentation. Children learn to segment written words into relevant components and thus foster their orthographic representations (their knowledge about written words in long-term memory). The game is a digitized version of the task "draw syllable arc", commonly used in learning therapy to improve syllable analysis [30]. Again, we enhanced the commonly used version with emphasis on syllable stress - the syllable arc ought to be drawn deeper for stressed than for unstressed syllables, as can be seen in Figure 6 .

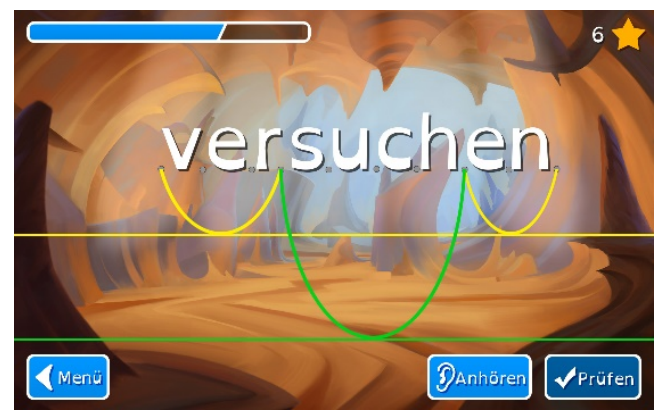

Figure 6. "Syllable Arcs". Children need to draw syllable arcs for the word ver-su-chen (to try) to mark syllable boundaries. Deeper arcs are drawn for stressed syllables. 


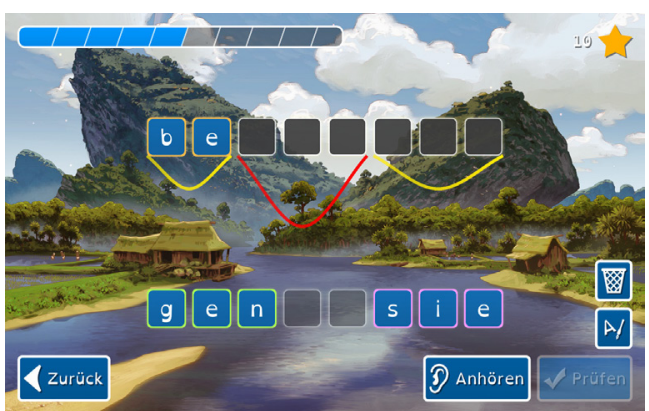

a. Easy difficulty level: besiegen (to win).

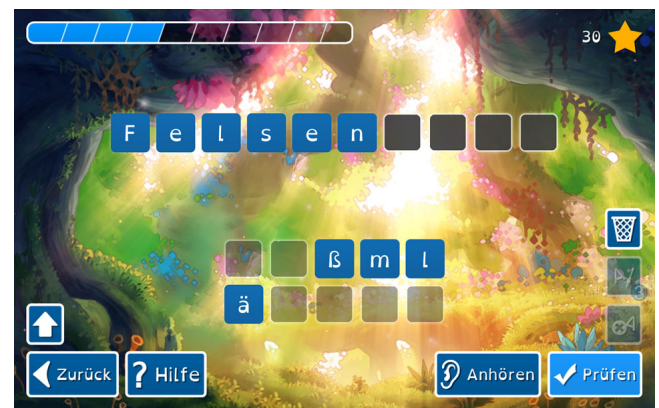

b. Hard difficulty level: Felsen (rock).

Figure 7. Spelling. a) The word be-sie-gen (to win) needs to be spelled. Syllable arcs indicate syllable stress and vowel length. Syllables are indicated by same-color border of letters. b) Consolidation task for the word Fel-sen (rock). No syllable arcs are drawn, number of letters is not exposed and letters leading to homophonic misspellings are added as distractors.

\subsubsection{Prosodiya congruency}

In chapter five of Prosodiya, children are taught that the rules they have learned in the previous chapters do not account for all word forms. To learn that the rules are only applicable to the basic (uninflected) form of a word, children have to recognize which words are in a 'Prosodiya-ish' form. This exercises bridges the gap from Prosodiya's first module to the second module that focuses on morphologic training, i.e. to learn to deduce that gewinnt (he wins) is spelled with an ambisyllabic consonant doubling as it's derived from gewinnen (to win).

\subsubsection{Spelling}

The first module of Prosodiya ends with a chapter about spelling. In this game, the children learn to apply and foster their previously learned skills by spelling words. They do so by dragging-and-dropping letters from a predefined set to form the word.

This exercise comes with several difficulties which are provided by adjusting the parameters 'letters' and 'syllable arcs'. The set of letters to spell a given word may i) only consist of the exact letters of the words, resulting in a letter-arrangement task as can be seen in Figure 7a, ii) also contain letters that do not share phonological similarities to any letter of the word, resulting in a letter discrimination task, or iii) contain distracting letters that would lead to homophonic (words that sound alike) misspellings (e.g., Fel-lsen instead of Fel-sen, see Figure 7b). To help link the awareness of orthographic markers to the stressed syllables, syllable arcs are drawn underneath the target input field in some conditions, depending on the individual difficulty. The color of the syllable arcs refer to syllable stress and vowel length (yellow for unstressed syllables, red for open stressed syllables, blue for closed stressed syllables).

To support scaffolding feedback, individual letters can be solved or distractor letters can be deleted after the children misspell a word.

It is our intention that, at the end of the first module of Prosodiya, children should have improved: the perception and production of syllable stress, vowel length distinction, identification of syllable boundaries, recognition of orthographic markers, and, finally, spelling words in basic forms.

\subsection{Visual aesthetic design}

The visual aesthetic design of Prosodiya follows three design principles to be appealing, consistent, and simple [76]. To address the first principle, we are collaborating with a renowned comic artist and licensed images from the comic "The Wormworld Saga" (https://wormworldsaga.com) as background images for our game. We adjusted the high quality images to fit our needs regarding story, atmosphere, and mechanics of our game. 
We have chosen a fantasy-themed setting for Prosodiya due to the fact that embedding learning activities in fantasy contexts has proven to be beneficial for motivation, involvement, and learning (e.g., [77]). Based on the background images, we also crafted a map of Prosodiya that is used as level selection and to show overall progress within the game, see Figure 2. The background images change during game play continuously and represent places of the world map.

Our pedagogical agents, the Kugellichter, were also carefully designed to engage children and facilitate learning. Their round shapes may induce positive emotions that facilitate learning and improve comprehension [78]. The agents have three distinguishable properties, i.e. color, size, and mouth, to facilitate memorizing their linguistic property in game play.

The pictures representing words (e.g., Figure 5) have also been designed iteratively to fit in the game's overall look and feel and to describe the word as best as possible.

We use OpenDyslexic [79] as font because it has been specifically designed for dyslexics in appropriate sizes. Buttons were kept as simple as possible using icons supplementary to text in order to minimize the effort to read unrelated information, with which young or dyslexic children may struggle.

To keep it simple, we have limited the game screen to game elements required by the respective activity and forego additional elements that might distract the learner or hinder learning.

Overall, the visual appearance of Prosodiya is intended to increase the perception of positive affect and immersion and to highlight the content to be learned.

\subsection{Narrative design}

The narrative of Prosodiya provides information on the content to be learned and game mechanics as well as to be an incentive and to increase self-perception of progression.

The narrative of Prosodiya reflects worries and needs of families of children with dyslexia: Prosodiya is haunted by a mysterious fog that has covered all of the peaceful land, causing the inhabitants to live a live full of worries and sorrows. This relates to affected children who often experience the difficulties of literacy acquisition as an impenetrable fog. In a way that the story deals with real-life struggles of affected children, we wanted to positively affect children's lives beyond the game's world. The game aims at helping children to "see clearly again" and feel comfortable within the world of reading and writing. Progressing through the world of Prosodiya and deliberating the world's places from the mischievous should ideally reflect the progress of learner's literacy acquisition.

In the current version of Prosodiya, the active continuation of the storyline is limited to a prologue in form of a cutscene and the interactive tutorials to continue the storyline. However, the map of Prosodiya and a change of background images in game activities implicitly continue the storyline. In future development, additional cutscenes will be included to actively tell the full story in order to contribute to the game's stickiness.

\subsection{Incentive system}

Prosodiya uses intrinsic and extrinsic motivational elements to encourage learners to continue playing with Prosodiya.

Regarding extrinsic rewards, children can collect points (see top right corner of the game screen) and receive encouraging responses from the pedagogical agents in the game activities when answering correctly. More points are given when they solve a task at the first go to avoid trial-and-error behavior.

Depending on children's performance, subsequent game content may be unlocked. To provide high replay value and to increase training effects, we use a 1-3 star rating (i.e. more stars for higher performance) for each level displayed underneath each level on the world map. 
Intrinsic rewards cover increased knowledge of the children, increasing complexity of tasks and words to make for new challenges, and the story progression.

For future development, we are planning that children may redeem collected points to buy a dragon egg, incubate it, and raise the hatched dragon to be their companion within the world of Prosodiya and to play bonus games with. With this, we aim to support longterm motivation and give children a place within the game where they can relax and ease their mind.

\subsection{Musical score}

The musical score of Prosodiya consists of ambient music in the level selection, feedback used to acknowledge correct and incorrect responses, as well as voices of the pedagogical agents.

Regarding feedback to tasks, the game responds to correct answers by playing pleasant sounds and praising the children with short expressions spoken by the pedagogical agents. A different, more sophisticated sound is played if the task was solved at the first go. If wrong answers are logged in, children are encouraged to try again.

When present, the pedagogical agents give spoken feedback. Pedagogical agents also explain game mechanics and learning goals in tutorials. Professional speakers have lent their voices to the pedagogical agents with a special focus on positive affect and emphasizing individual characteristics relating to the linguistic property represented by the agent. This affective encouragement may also positively affect children's performance (cf. $[80])$.

\subsection{Results of a pilot study}

We conducted a pilot study with a preliminary version of Prosodiya during a period of six weeks in winter 2014/2015 with 11 dyslexic children to primarily investigate feasibility and user experience. The preliminary version included the first two games ("Stress Pattern", "Syllable Structure") and a limited version of the third game ("Orthographic Markers"). A limited vocabulary of 220 words was used. We reported the results in the corresponding conference paper in detail [45] and will summarize the findings:

The results of questionnaires handed out to children and parents indicate: children enjoyed playing the game, the children's motivation could be maintained during the period, children and parents would continue to use Prosodiya and request for more exercises, children and parents perceived self-efficacy, the graphical appearance of Prosodiya is appealing, and the pedagogical agents are well perceived. However, the results also made the following drawbacks apparent: tutorials of the preliminary versions were perceived by some of the children to be too complicated and too long, and some children reported that the objective of an exercise was not always obvious. We have addressed these issues by facilitating and shortening the tutorials and introduced tooltips for each type of task (Figure $4 b)$.

Overall, in spelling as well as in reading, approximately half of the children of the current sample improved their performance. About a third did not change in performance, and two children performed worse. Overall, the best improvements were obtained in speed reading comprehension tests. Due to the limitations of the study of no control group and not including explicit spelling training, implications must be drawn with caution.

\section{Conclusion and outlook}

In this article, we have reflected the state of research of the relation of syllable stress and literacy acquisition. We then have examined advantages and disadvantages of therapeutic (TI), computer-based (CBI), and digital game-based interventions (DGBI) to treat reading and spelling disorders. We conclude that dyslexic children should receive evidence-based 
TIs as soon as possible and as long as necessary and in addition use evidence-based DGBIs to maximize engagement, motivation, and learning until their reading and spelling proficiencies enables them to participate in social, cultural, and educational life on an ageappropriate level. The disadvantages of TIs of being cost-intensive, dependent on time, location, and tutor may be addressed by DGBIs that can be used autonomously by children within or outside of class while offering unique opportunities to (re-) engage and motivate learners. As our literature review revealed, there is a lack of DGBIs for the treatment of spelling disorders in German dyslexic children.

Given the potential of DGBIs, we proposed our mobile serious game "Prosodiya" for German dyslexic primary school children. By utilizing the building blocks of game design for learning proposed by Plass et al. [53], i.e. game mechanics, visual aesthetic design, narrative design, an incentive system, musical score, and content and skills, we examined how Prosodiya contributes to the state of the art of computer-based interventions for German dyslexic children. Prosodiya focusses on teaching the relation between syllable stress, vowel length, and orthographic markers to improve reading and spelling. We examined the various evidence-based trainings included in Prosodiya. To sum up, the contributions of Prosodiya to date are: i) teaching the perception and production of syllable stress, ii) relating the stressed syllable's linguistic characteristics to vowel length and orthographic marking, iii) including mouth motor activities to facilitate the improvement of phonological awareness, while iv) balancing aforementioned learning objectives with the design of game play to engage and motivate learners and maximize learning. Lastly, we aim to explore and integrate approaches of embodied trainings to support and facilitate learning. DGBIs offer unique opportunities to incorporate sensor-based embodied trainings in a way that children practice on their own, without the need of human instructors, engaging learners on a behavioral and cognitive level [53].

More specifically, our first approach of using embodied trainings will address the games of "syllable arcs" (see Section 4.1.2). While we already tested a preliminary version of the game called "swing the stress pattern", it is still under development. The embodied game consists of two parts. At first, children swing with customary fitness trackers on their hand the stress pattern of the word (see Figure 8a). That is, instead of drawing a syllable arc on the touchscreen, children are required to use their (whole) body to execute deep or shallow swings. Spelling the syllables is the second part of the game. Children do so by placing the letters in their corresponding syllable arcs, similar to Section 4.1.4. The first part is considered an embodied training, a novelty in the area of mobile serious games. Embodied trainings - interventions mapping (whole) body movements and gestures to key features of learning content - can be used to additionally support learning-impaired children in learning therapy. The concept of embodied trainings is based on the theory of embodied cognition [81]. Influencing the learning process positively with body movement and embodied experience, the aims of such physical interventions are the development of embodied memory aids to foster learning, to ease mental effort and demands of working memory, and to be more fun. The positive effect of gesturing on learning was shown for various areas, for example gesturing while learning a new arithmetical strategy resulted in a better retention of knowledge [82] or acting out movements or gestures of animals increased the learning of their names in a foreign language [83].Embodied trainings are already part of many analogous interventions for learning disorders, for example embodied number-line estimation tasks for children with dyscalculia $[48,84]$ or the so-called "swing the syllables" $[69,85]$ for dyslexic children. Besides analogous interventions, research on computer-based embodied trainings provides evidence for the positive impact on learning. For example, [86] have shown that computer-based embodied trainings helped children to foster the acquisition of basic numerical competencies significantly better than counterparts without (or with less) embodiment. We digitized and enhanced the embodied training "swing the syllables". By "dancing" the speech rhythm, children learn to segment words into syllables and identify their stress pattern. 
pag. 54

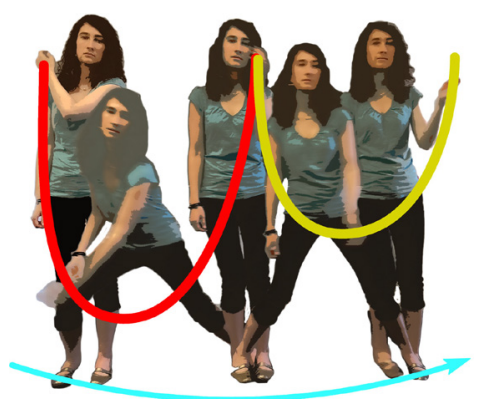

a. Stress pattern swung for a disyllabic trochee (e.g., Bie-ne, bee).

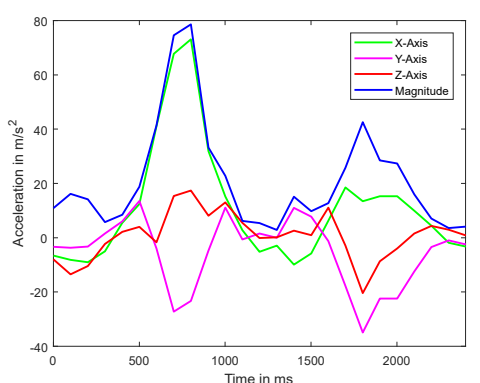

b. Acceleration recorded with wearable.

Figure 8. a) Embodied training "Swing the Stress Pattern”. Children speak each syllable clearly and loudly, simultaneously do a sidestep, and swing their writing hand from their left to their right shoulder. Deeper and more emphasized swing is performed for stressed syllables. b) Acceleration values recorded with a fitness tracker worn on children's wrist.

They are instructed to speak each syllable clearly and loudly, simultaneously do a sidestep, and swing their writing hand from their left to their right shoulder, see Figure 8a. A deeper and more emphasized swing is performed for stressed syllables. Swinging the speech rhythm of words, children are expected to improve their reading and writing performance by systematically fostering syllable awareness. In contrast to the original intervention, we again distinguish between stressed and unstressed syllables.

To include this embodied training into Prosodiya, we are developing a system that recognizes the movements of the children and classifies the stress pattern they have swung [87]. We use built-in accelerometers of customary fitness trackers to record movement and to classify syllable stress. Our user tests throughout the development highlight three important challenges that arise when sensor-based embodied trainings are developed for children: First, fitness trackers should be used due to size and comfort. Smartphones are too big for children's hands causing restricted movement, even when the Smartphone is attached securely with a wrist wrap. Second, systems have to be adjusted to the children's behavior and needs. Prominent features that were used to classify the gestures with adults are less reliable when performed by children and need to be refined or changed. Lastly, performing the gestures correctly cannot be expected but must be learned and trained extensively. Stressed syllables were often swung weaker or hardly distinguishable from unstressed ones. It is not clear whether this is caused by the lack of the awareness of syllable stress or by missing feedback about swing intensity. We therefore will integrate an intensive learning phase where a character of the game's world will explain extensively the principle of syllable stress and the intended use of the gestures and give qualitative feedback on the performed gestures. Overall, our results and systematic literature research encourage the approach to develop embodied trainings with simple, body-based interactions using builtin accelerometers of Smartphones and fitness trackers. This is, to the best of our knowledge, the first embodied training in a mobile serious game that evaluates movement and gestures. Other games already include the instruction to perform embodied trainings but do not evaluate the children's response (e.g., [88]). In contrast, we display the classified stress pattern on the game screen with corresponding syllable arcs.

To evaluate the therapeutic approach of Prosodiya empirically and validate the positive indications of our pilot study, we are conducting a randomized controlled field trial with a waiting control group design in spring/summer of 2018. One hundred and twenty-nine primary-school children are participating and are practicing with Prosodiya for a duration of 8-10 weeks. Approximately 70 children are poor readers and/or spellers. According to the training plan, children are asked to practice with Prosodiya five days per week, 20 minutes per day. 


\section{Acknowledgements}

This research was funded by the LEAD Graduate School \& Research Network [GSC1028], a project of the Excellence Initiative of the German federal and state governments. Heiko Holz is a doctoral student at the LEAD Graduate School \& Research Network.

\section{References}

[1] Moll, K., Kunze, S., Neuhoff, N., Bruder, J., Schulte-Körne, G., Specific Learning Disorder: Prevalence and Gender Differences, PLoS One, Vol. 9, Nr. 7, 2014. https://doi.org/10.1371/journal.pone.0103537

[2] Moll, K., Landerl, K., Double Dissociation Between Reading and Spelling Deficits, Sci. Stud. Read., Vol. 13, Nr. 5, 2009. https://doi.org/10.1080/10888430903162878

[3] Katusic, S.K., Colligan, R.C., Barbaresi, W.J., Schaid, D.J., Jacobsen, S.J., Incidence of reading disability in a population-based birth cohort, 1976-1982, Rochester, Minn, Mayo Clin. Proc., Vol. 76, Nr. 11, 2001. https://doi.org/10.4065/76.11.1081

[4] Schulte-Körne, G., Remschmidt, H., Legasthenie - Symptomatik, Diagnostik, Ursachen, Verlauf und Behandlung, Dtsch Arztebl Int., Vol. 100, Nr. 7, 2003.

[5] Bender, F., Brandelik, K., Jeske, K., Lipka, M., Löffler, C., Mannhaupt, G., Naumann, C.L., Nolte, M., Ricken, G., Rosin, H., Scheerer-Neumann, G., von Aster, M., von Orloff, M., Die integrative Lerntherapie, Lernen und Lernstörungen, Vol. 6, Nr. 2, 2017. https://doi.org/10.1024/2235-0977/a000167

[6] Daniel, S.S., Walsh, A.K., Goldston, D.B., Arnold, E.M., Reboussin, B. a, Wood, F.B., Suicidality, School Dropout, and Reading Problems Among Adolescents, J. Learn. Disabil., Vol. 39, Nr. 6, 2006. https://doi.org/10.1177/00222194060390060301

[7] Beddington, J., Cooper, C.L., Field, J., Goswami, U., Huppert, F.A., Jenkins, R., Jones, H.S., Kirkwood, T.B.L., Sahakian, B.J., Thomas, S.M., The mental wealth of nations, Nature, Vol. 455, Nr. 7216, 2008. https://doi.org/10.1038/4551057a

[8] Abrami, P., Borohkovski, E., Lysenko, L., The Effects of ABRACADABRA on Reading Outcomes: A Meta-Analysis of Applied Field Research, J. Interact. Learn. Res., Vol. 26, Nr. 4, 2015.

[9] Kargl, R., Purgstaller, C., Weiss, S., Fink, A., Effektivitätsüberprüfung eines morphemorientierten Grundwortschatz-Segementierungstrainings (MORPHEUS) bei Kindern und Jugendlichen, Heilpädagogische Forsch., Vol. 34, Nr. 3, 2008.

[10]Klatte, M., Bergström, K., Steinbrink, C., Konerding, M., Lachmann, T., "Effects of the Computer-Based Training Program Lautarium on Phonological Awareness and Reading and Spelling Abilities in German Second-Graders", In Lachmann, T. and Weis, T. (Eds.), Reading and Dyslexia: From Basic Functions to Higher Order Cognition, Springer International Publishing, Cham, 2018. https://doi.org/10.1007/978-3-319-90805-2 15

[11] Kyle, F., Kujala, J., Richardson, U., Lyytinen, H., Goswami, U., Assessing the effectiveness of two theoretically motivated computer-assisted reading interventions in the United Kingdom: GG Rime and GG Phoneme, Read. Res. Q., Vol. 48, Nr. 1, 2013. https://doi.org/10.1002/rrq

[12][Lenhard, W., Lenhard, A., Evidenzbasierte Förderung schulischer Fertigkeiten am Computer: Lernspiele mit Elfe und Mathis, Förderprogramme für Vor. und Grundschule, Vol. 2006, 2016.

[13]Deterding, S., Dixon, D., Khaled, R., Nacke, L., "From Game Design Elements to Gamefulness: Defining 'Gamification'", In Proceedings of the 15th International Academic MindTrek Conference: Envisioning Future Media Environments, ACM, New York, NY, USA, 2011. https://doi.org/10.1145/2181037.2181040

[14]Boyle, E.A., Hainey, T., Connolly, T.M., Gray, G., Earp, J., Ott, M., Lim, T., Ninaus, M., Ribeiro, C., Pereira, J., An update to the systematic literature review of empirical evidence of the impacts and outcomes of computer games and serious games, Comput. Educ., Vol. 94, Nr. Supplement C, 2016. https://doi.org/10.1016/j.compedu.2015.11.003

[15]Berkling, K., "Phontasia: A phonics game for German and its effect on orthographic skills-first corpus explorations", In WOCCI 2017: 6th International Workshop on Child Computer Interaction, ISCA, ISCA, 2017. https://doi.org/10.21437/WOCCI.2017-2 
[16] Kast, M., Baschera, G.-M., Gross, M., Jäncke, L., Meyer, M., Computer-based learning of spelling skills in children with and without dyslexia, Ann. Dyslexia, Vol. 61, Nr. 2, 2011. https://doi.org/10.1007/s11881-011-0052-2

[17] Rello, L., Bayarri, C., Otal, Y., Pielot, M., "A computer-based method to improve the spelling of children with dyslexia", In Proceedings of the 16th international ACM SIGACCESS conference on Computers \& accessibility - ASSETS '14, ACM Press, New York, New York, USA, 2014. https://doi.org/10.1145/2661334.2661373

[18]Bradley, L., Bryant, P.E., Categorizing sounds and learning to read-a causal connection, Nature, Vol. 301, Nr. 5899, 1983. https://doi.org/10.1038/301419a0

[19] Goswami, U., Mead, N., Fosker, T., Huss, M., Barnes, L., Leong, V., Impaired perception of syllable stress in children with dyslexia: A longitudinal study, J. Mem. Lang., Vol. 69, Nr. 1, 2013. https://doi.org/10.1016/j.jml.2013.03.001

[20]Leong, V., Hämäläinen, J., Soltész, F., Goswami, U., Rise time perception and detection of syllable stress in adults with developmental dyslexia, J. Mem. Lang., Vol. 64, Nr. 1, 2011. https://doi.org/10.1016/j.jml.2010.09.003

[21] Sauter, K., Heller, J., Landerl, K., Sprachrhythmus und Schriftspracherwerb, Lernen und Lernstörungen, Vol. 1, Nr. 4, 2012. https://doi.org/10.1024/2235-0977/a000023

[22] Kohler, K.J., "Invariance and variability in speech timing: From utterance to segment in German", In Perkell, J.S. and Klatt, D.H. (Eds.), Invariance and Variability in Speech Processes, Erlbaum, Hillsdale, 1986.

[23] Jiménez-Fernández, G., Gutiérrez-Palma, N., Defior, S., Impaired stress awareness in Spanish children with developmental dyslexia, Res. Dev. Disabil., Vol. 37, 2015. https://doi.org/10.1016/j.ridd.2014.11.002

[24] Brandelik, K., Sprachrhythmische Fähigkeiten im Schriftspracherwerb, Südwestdeutscher Verlag für Hochschulschriften, 2014.

[25] Staffeldt, S., Einführung in die Phonetik, Phonologie und Graphematik des Deutschen. Ein Leitfaden für den akademischen Unterricht, Stauffenburg, Tübingen, 2010.

[26] Landerl, K., Categorization of vowel length in German poor spellers: An orthographically relevant phonological distinction, Appl. Psycholinguist., Vol. 24, Nr. 4, 2003. https://doi.org/10.1017/S0142716403000262

[27] Klicpera, C., Gasteiger Klicpera, B., Sind Rechtschreibschwierigkeiten Ausdruck einer phonologischen Störung?, Z. Entwicklungspsychol. Padagog. Psychol., Vol. 32, Nr. 3, 2000. https://doi.org/10.1026//0049-8637.32.3.134

[28] Bhide, A., Power, A., Goswami, U., A rhythmic musical intervention for poor readers: A comparison of efficacy with a letter-based intervention, Mind, Brain, Educ., Vol. 7, Nr. 2, 2013. https://doi.org/10.1111/mbe.12016

[29] Thomson, J.M., Leong, V., Goswami, U., Auditory processing interventions and developmental dyslexia: a comparison of phonemic and rhythmic approaches, Read. Writ., Vol. 26, Nr. 2, 2013. https://doi.org/10.1007/s11145-012-9359-6

[30] Galuschka, K., Schulte-Körne, G., Clinical practice guideline: The diagnosis and treatment of reading and/or spelling disorders in children and adolescents, Dtsch Arztebl Int., Vol. 113, Nr. 16, 2016. https://doi.org/10.3238/arztebl.2016.0279

[31] Galuschka, K., Ise, E., Krick, K., Schulte-Körne, G., Effectiveness of Treatment Approaches for Children and Adolescents with Reading Disabilities: A Meta-Analysis of Randomized Controlled Trials, PLoS One, Vol. 9, Nr. 2, 2014. https://doi.org/10.1371/journal.pone.0089900

[32] McArthur, G., Eve, P.M., Jones, K., Banales, E., Kohnen, S., Anandakumar, T., Larsen, L., Marinus, E., Wang, H.-C., Castles, A., Phonics training for English-speaking poor readers, $\begin{array}{llllll}\text { Cochrane Database } & \text { Syst. } & \text { Rev., } & \text { Nr. } & 12, & 2012 .\end{array}$ https://doi.org/10.1002/14651858.CD009115.pub2

[33] Aro, M., Learning to read: the effect of orthography, 2004.

[34] Landerl, K., Wimmer, H., Frith, U., The impact of orthographic consistency on dyslexia: A German-English comparison, Cognition, Vol. 63, Nr. 3, 1997. https://doi.org/https://doi.org/10.1016/S0010-0277(97)00005-X

[35] Rau, A.K., Moll, K., Snowling, M.J., Landerl, K., Effects of orthographic consistency on eye movement behavior: German and English children and adults process the same words differently, J. Exp. Child Psychol., Vol. 130, 2015. https://doi.org/10.1016/j.jecp.2014.09.012

[36] Tacke, G., Evaluation eines Lesetrainings zur Förderung lese-rechtschreibschwacher Grundschüler der zweiten Klasse, Psychol. Erziehung und Unterr., Vol. 52, Nr. 3, 2005.

[37] Groth, K., Hasko, S., Bruder, J., Kunze, S., Schulte-Körne, G., Interventionseffekte bei LeseRechtschreibstörung: Evaluation von zwei Förderkonzepten unter besonderer Betrachtung 
methodischer Aspekte, Lernen und Lernstörungen, Vol. 2, Nr. 3, 2013. https://doi.org/10.1024/2235-0977/a000038

[38] Klicpera, C., Weiss, J., Gasteiger-Klicpera, B., Erfolg einer schulischen LegasthenikerFörderung für Kinder der 3. und 4. Schulstufe nach dem Programm von Reuter-Liehr, Heilpädagogische Forsch., Vol. 39, Nr. 2, 2013.

[39] Ise, E., Schulte-Körne, G., Spelling deficits in dyslexia: Evaluation of an orthographic spelling training, Ann. Dyslexia, Vol. 60, Nr. 1, 2010. https://doi.org/10.1007/s11881-010-0035-8

[40] Ise, E., Engel, R.R., Schulte-Körne, G., Was hilft bei der Lese-Rechtschreibstörung? Ergebnisse einer Metaanalyse zur Wirksamkeit deutschsprachiger Förderansätze, Kindheit und Entwicklung, Vol. 21, Nr. 2, 2012. https://doi.org/10.1026/0942-5403/a000077

[41]Drigas, A., Batziaka, E., Dyslexia and ICTs, Assessment and Early Intervention in Kindergarten, Int. J. Emerg. Technol. Learn., Vol. 11, Nr. 02, 2016. https://doi.org/10.3991/ijet.v11i02.5193

[42] Cidrim, L., Madeiro, F., Information and Communication Technology (ICT) applied to dyslexia: literature review, Rev. CEFAC, Vol. 19, Nr. 1, 2017. https://doi.org/10.1590/1982021620171917916

[43] Berninger, V.W., Nagy, W., Tanimoto, S., Thompson, R., Abbott, R.D., Computer instruction in handwriting, spelling, and composing for students with specific learning disabilities in grades 4-9, Comput. Educ., Vol. 81, 2015. https://doi.org/10.1016/j.compedu.2014.10.005

[44] Ronimus, M., Kujala, J., Tolvanen, A., Lyytinen, H., Children's engagement during digital game-based learning of reading: The effects of time, rewards, and challenge, Comput. Educ., Vol. 71, 2014. https://doi.org/10.1016/i.compedu.2013.10.008

[45] Ninaus, M., Kiili, K., Mcmullen, J., Moeller, K., Assessing fraction knowledge by a digital game, Comput. Human Behav., Vol. 70, 2017. https://doi.org/10.1016/j.chb.2017.01.004

[46] Sense, F., Behrens, F., Meijer, R.R., van Rijn, H., "Stability of Individual Parameters in a Model of Optimal Fact Learning", In Proceedings of the 13th International Conference on Cognitive Modeling, 2015.

[47] Stock, C., Schneider, W., PHONIT: Ein Trainingsprogramm zur Verbesserung der phonologischen Bewusstheit und Rechtschreibleistung im Grundschulalter, Hogrefe, Göttingen, 2011.

[48] Kaasa health GmbH, Meister Cody - Namagi, https://www.meistercody.com/produkte/namagilegasthenie/

[49] Holz, H., Brandelik, K., Brandelik, J., Beuttler, B., Kirsch, A., Heller, J., Meurers, D., "Prosodiya - A Mobile Game for German Dyslexic Children", In Dias, J., Santos, P.A., and Veltkamp, R.C. (Eds.), Games and Learning Alliance: 6th International Conference, GALA 2017, Lisbon, Portugal, December 5--7, 2017, Proceedings, 2017. https://doi.org/10.1007/9783-319-71940-5 7

[50] Björklund, M., Dyslexic Students: Success Factors for Support in a Learning Environment, J. Acad. Librariansh., Vol. 37, Nr. 5, 2011. https://doi.org/10.1016/j.acalib.2011.06.006

[51]Huotari, K., Hamari, J., "Defining Gamification: A Service Marketing Perspective", In Proceeding of the 16th International Academic MindTrek Conference, ACM, New York, NY, USA, 2012. https://doi.org/10.1145/2393132.2393137

[52] Hamari, J., Koivisto, J., Sarsa, H., "Does Gamification Work? - A Literature Review of Empirical Studies on Gamification", In 2014 47th Hawaii International Conference on System Sciences, IEEE, 2014. https://doi.org/10.1109/HICSS.2014.377

[53] Plass, J.L., Homer, B.D., Kinzer, C.K., Foundations of Game-Based Learning, Educ. Psychol., Vol. 50, Nr. 4, 2015. https://doi.org/10.1080/00461520.2015.1122533

[54] Wouters, P., van Nimwegen, C., van Oostendorp, H., van der Spek, E.D., A meta-analysis of the cognitive and motivational effects of serious games., J. Educ. Psychol., Vol. 105, Nr. 2, 2013. https://doi.org/10.1037/a0031311

[55] Kerawalla, L., Crook, C., From promises to practices: The fate of educational software in the home, Technol. Pedagog. Educ., Vol. 14, Nr. 1, 2005. https://doi.org/10.1080/14759390500200195

[56] Ronimus, M., Lyytinen, H., Is School a Better Environment Than Home for Digital Game-Based Learning? The Case of GraphoGame, Hum. Technol. An Interdiscip. J. Humans ICT Environ., Vol. 11, Nr. 2, 2015. https://doi.org/10.17011/ht/urn.201511113637

[57] Gee, J.P., What video games have to teach us about learning and literacy, Comput. Entertain., Vol. 1, Nr. 1, 2003. https://doi.org/10.1145/950566.950595

[58] Prensky, M., Digital game-based learning, Comput. Entertain., Vol. 1, Nr. 1, 2003. https://doi.org/10.1145/950566.950596 
[59]Ke, F., Abras, T., Games for engaged learning of middle school children with special learning needs, Br. J. Educ. Technol., Vol. 44, Nr. 2, 2013. https://doi.org/10.1111/j.14678535.2012.01326.x

[60] Holmes, W., Using game-based learning to support struggling readers at home, Learn. Media Technol., Vol. 36, Nr. 1, 2011. https://doi.org/10.1080/17439884.2010.531023

[61] Griffiths, M., The educational benefits of videogames, Educ. Heal., Vol. 20, Nr. 3, 2002.

[62] Squire, K.D., Video Games and Education: Designing Learning Systems for an Interactive Age, Educ. Technol., Vol. 48, Nr. 2, 2008.

[63] Homer, B.D., Kinzer, C.K., Plass, J.L., Letourneau, S.M., Hoffman, D., Bromley, M., Hayward, E.O., Turkay, S., Kornak, Y., Moved to learn: The effects of interactivity in a Kinect-based literacy game for beginning readers, Comput. Educ., Vol. 74, 2014. https://doi.org/10.1016/j.compedu.2014.01.007

[64] Arnab, S., Lim, T., Carvalho, M.B., Bellotti, F., de Freitas, S., Louchart, S., Suttie, N., Berta, R., De Gloria, A., Mapping learning and game mechanics for serious games analysis, Br. J. Educ. Technol., Vol. 46, Nr. 2, 2015. https://doi.org/10.1111/bjet.12113

[65] Quinn, C.N., Engaging learning: designing e-learning simulation games, Jossey-Bass, Quinn2005, 2005.

[66]Berkling, K., Pflaumer, N., Phontasia - a Phonics Trainer for German Spelling in Primary Education, Proc. 4th Work. Child Comput. Interact. (WOCCI 2014), Nr. Wocci, 2014.

[67] Berkling, K., Pflaumer, N., Lavalley, R., "German Phonics Game using Speech Synthesis - A Longitudinal Study about the Effect on Orthography Skills", In Workshop on Spoken Language Technology for Education (SLaTE), 2015.

[68] Reid, G., Strnadová, I., Cumming, T., Expanding horizons for students with dyslexia in the 21st century: Universal design and mobile technology, J. Res. Spec. Educ. Needs, Vol. 13, Nr. 3, 2013. https://doi.org/10.1111/1471-3802.12013

[69]Reuter-Liehr, C., Behandlung der Lese-Rechtschreibschwäche nach der Grundschulzeit: Anwendung und Überprüfung eines Konzeptes, Z. Kinder. Jugendpsychiatr., Vol. 21, Nr. 3, 1993.

[70] Snowling, M.J., Phonological processing and developmental dyslexia, J. Res. Read., Vol. 18, Nr. 2, 1995. https://doi.org/10.1111/j.1467-9817.1995.tb00079.x

[71] Berninger, V.W., Winn, W.D., Stock, P., Abbott, R.D., Eschen, K., Lin, S.J., Garcia, N., Anderson-Youngstrom, M., Murphy, H., Lovitt, D., Trivedi, P., Jones, J., Amtmann, D., Nagy, W., Tier 3 specialized writing instruction for students with dyslexia, Read. Writ., Vol. 21, Nr. 1-2, 2008. https://doi.org/10.1007/s11145-007-9066-x

[72]Kirk, C., Gillon, G.T., Integrated Morphological Awareness Intervention as a Tool for Improving Literacy, Lang. Speech Hear. Serv. Sch., Vol. 40, Nr. 3, 2009. https://doi.org/10.1044/0161-1461(2008/08-0009)

[73] Moll, K., Wallner, R., Landerl, K., Kognitive Korrelate der Lese-, Leserechtschreib- und der Rechtschreibstörung, Lernen und Lernstörungen, Vol. 1, Nr. 1, 2012. https://doi.org/10.1024/2235-0977/a000002

[74] Boyer, N., Ehri, L.C., Contribution of Phonemic Segmentation Instruction With Letters and Articulation Pictures to Word Reading and Spelling in Beginners, Sci. Stud. Read., Vol. 15, Nr. 5, 2011. https://doi.org/10.1080/10888438.2010.520778

[75]Kargl, R., Purgstaller, C., Morphemunterstütztes Grundwortschatz- Segmentierungstraining, Hogrefe, Göttingen, 2010.

[76] Berkling, K., Faller, H., Piertzik, M., "Avoiding Failure in Modern Game Design with Academic Content - A Recipe, an Anti-Pattern and Applications Thereof", In Proceedings of the 9th International Conference on Computer Supported Education, 2017. https://doi.org/10.5220/0006281800250036

[77] Parker, L.E., Lepper, M.R., Bartholomew, K., Cordova, D., Mayer, J., Effects of fantasy contexts on children's learning and motivation: Making learning more fun., J. Pers. Soc. Psychol., Vol. 62, Nr. 4, 1992. https://doi.org/10.1037/0022-3514.62.4.625

[78] Plass, J.L., Heidig, S., Hayward, E.O., Homer, B.D., Um, E., Emotional design in multimedia learning: Effects of shape and color on affect and learning, Learn. Instr., Vol. 29, 2014. https://doi.org/10.1016/j.learninstruc.2013.02.006

[79] Gonzalez, A., OpenDyslexic, https://www.opendyslexic.org/.

[80] Schmitt, K.L., Hurwitz, L.B., Duel, L.S., Linebarger, D.L.N., Nichols Linebarger, D.L., Learning through play: The impact of web-based games on early literacy development, Comput. Human Behav., Vol. 81, 2018. https://doi.org/10.1016/j.chb.2017.12.036 
[81] Glenberg, A., Witt, J., Metcalfe, J., From the Revolution to Embodiment 25 Years of Cognitive Psychology, Perspect. Psychol. Sci., Vol. 8, Nr. 5, 2013. https://doi.org/10.1177/1745691613498098

[82] Cook, S.W., Mitchell, Z., Goldin-Meadow, S., Gesturing makes learning last, Cognition, Vol. 106, Nr. 2, 2008. https://doi.org/10.1016/j.cognition.2007.04.010

[83] Toumpaniari, K., Loyens, S., Mavilidi, M.-F., Paas, F., Preschool Children's Foreign Language Vocabulary Learning by Embodying Words Through Physical Activity and Gesturing, Educ. Psychol. Rev., Vol. 27, Nr. 3, 2015. https://doi.org/10.1007/s10648-015-9316-4

[84] Link, T., Moeller, K., Huber, S., Fischer, U., Nuerk, H.C., Walk the number line - An embodied training of numerical concepts, Trends Neurosci. Educ., Vol. 2, Nr. 2, 2013. https://doi.org/10.1016/j.tine.2013.06.005

[85] Michel, H.-J., Freiburger Rechtschreibschule. Grundlagen - Diagnosemöglichkeiten praktische Übungen zum Thema LRS, AOL-Verlag, Buxtehude, 2006.

[86] Dackermann, T., Fischer, U., Nuerk, H., Cress, U., Moeller, K., Applying embodied cognition: from useful interventions and their theoretical underpinnings to practical applications, ZDM, 2017. https://doi.org/10.1007/s11858-017-0850-z

[87] Holz, H., Beuttler, B., Kirsch, A., "Bewegungserkennung mit Wearables für Embodied Trainings in Serious Games", In Burghardt, M., Wimmer, R., Wolff, C., and Womser-Hacker, C. (Eds.), Mensch und Computer 2017 - Tagungsband, Gesellschaft für Informatik e.V., Regensburg, 2017. https://doi.org/https://doi.org/10.18420/muc2017-mci-0368

[88] Ernst Klett Verlag GmbH, Deutsch Klasse 2 mit Zebra, https://www.klett.de/produkt/isbn/ECN20001APA99. 